\title{
Aerosolization of Aspergillus niger spores from colonies on different positions of a circular tube
}

\author{
Xian $\mathrm{Li}^{1}$, Tengfei Zhang ${ }^{1,2, *}$, and Shugang Wang ${ }^{1}$ \\ ${ }^{1}$ School of Civil Engineering, Dalian University of Technology (DUT), 116024 Dalian, China \\ ${ }^{2}$ School of Environmental Science and Engineering, Tianjin University, 300072 Tianjin, China
}

\begin{abstract}
Subject to the blowing air, fungal spores can be aerosolized from the colonies growing on cooling coils. The blowing air may accelerate and decelerate when passing a coil. The caused spore detachment may be different, when the fungal colonies grow on different positions of the coil. This study investigated the aerosolization of Aspergillus niger spores from a colony on a circular tube in a wind tunnel. The colony was first cultured in the carved groove along the longitudinal tube, and then the spores were aerosolized by a gradual increase of the blowing air speed. The grown colony on four different positions of the coil surface were blown for aerosolization. In addition, the airflow surrounding the circular tube was numerically solved to estimate the drag force for aerosolization of the spores. The results revealed that the collected airborne spores when the colonies were located tangentially to the upcoming airflow were six to eight times of those when the colonies were located parallel with the upcoming airflow for both the 4-day-old and 10-day-old colonies. The local air speeds in different positions of the tube were highly different from the inlet air speed of the wind tunnel. Such difference should be accounted for when estimating the drag force to aerosolize the fungal spores on the coils.
\end{abstract}

\section{Introduction}

Fungi in heating, ventilating, and air conditioning (HVAC) systems have caused increasing concern [1, 2]. Fungal spores and their metabolic byproducts contribute to inflammation, infection and asthma for occupants [3-5]. Subject to the blowing air, fungal propagules can be aerosolized from the HVAC system and then spread into the indoor air $[6,7]$.

Abundant biofilms of Penicillium viridicatum and Aspergillus niger (A. niger) were found growing on aluminum cooling coils of the HVAC system [8, 9]. As warm air gets into contact with the cooling coil, water condenses on the coil and forms water film [10]. The water film promotes airborne dust or fungal spores to stick to cooling coils, in which some dusts contain nutrients for fungal growth [11]. Fungal concentration on cooling coils was found up to $10^{4} \mathrm{CFU} / \mathrm{cm}^{2}$ [12].

Once a fungal colony has developed on a cooling coil, the coil may act as a source, releasing fungal propagules into the downstream air. The growing spores can be aerosolized from the coil surface, if the aerodynamic forces exceed the binding forces of fungal spores with their colonies [13, 14]. Both drag and lift forces constitute the major aerodynamic forces for spore detachment $[15$, 16]. The air speed has a remarkable effect on the aerodynamic forces. Spore release rates from moldy surfaces have been observed to increase with the speed of the sweeping air [17, 18]. Gusty airflow with high turbulence intensity was found more effective than steady wind in aerosolizing spores [19].

Note that when the air sweeps a coil, the flow may accelerate and decelerate near the coil. A stagnation point of the flow is formed on the windward side of the coil where the air speed is zero. A boundary layer is formed near the coil and the thickness of the boundary layer gradually increases when the flow passes the coil. The boundary layer may separate from the coil surface in the leeward side and a wake flow is developed nearby. In the leeward side of the coil the air speed is much lower than the upstream air speed [20]. Because of the difference of the air speed in different positions on the coil, the exerted aerodynamic forces to the growing fungal spores in different positions are different. The aerosolization of fungal spores from different positions of the coil can thus be different.

This study investigated the aerosolization of $A$. niger spores from a colony growing in different positions on a circular tube in a wind tunnel. Four different sweeping types to the colony, i.e., normally in the windward side, normally in the leeward side, tangentially in both sides, were studied. Numerical simulation of the airflow surrounding the circular tube was performed to estimate the drag force by the sweeping air for aerosolization of the fungal spores.

\section{Materials and methods}

* Corresponding author: tzhang@dlut.edu.cn 
For simplicity, aerosolization of the growing fungal spores on a single circular tube without fins was studied. The circular tube was installed in a wind tunnel for blowing. The A. niger was innoculated on a groove along the longitudinal tube. By rotating the tube, different sweeping types to the growing colony in the wind tunnel can be realized.

As shown in Fig. 1(A), the wind tunnel was composed of a centrifugal fan, a high-efficiency particulate air (HEPA) filter, a test section, a contraction section, and an exhaust filter. The fan forced air through the HEPA filter, and then the cleaned air swept the test circular tube with the growing $A$. niger colony on it. Some of the aerosolized spores were detected with a bioaerosol sensor after the contraction section. The blowing air speed was adjustable.

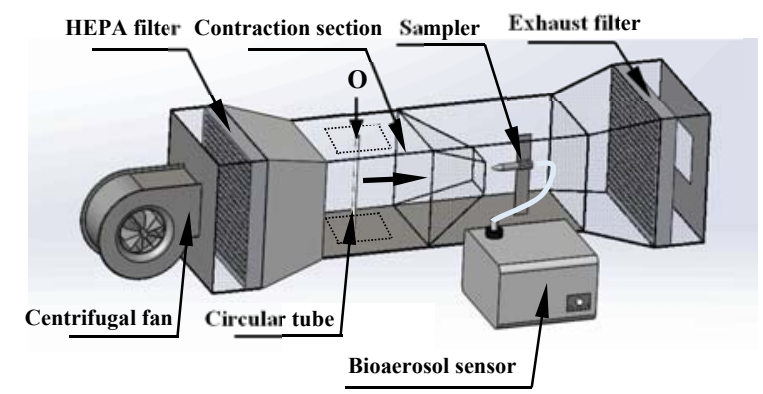

(A)

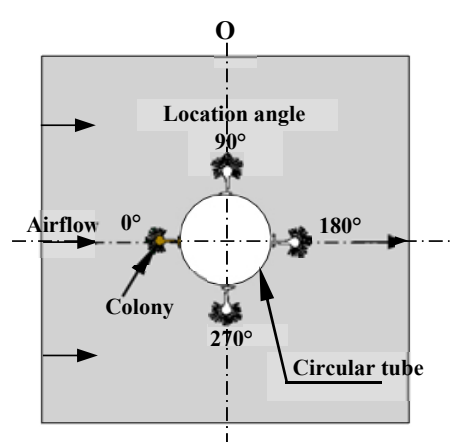

(B)

Fig. 1. Schematic diagram of wind tunnel for aerosolization of fungal spores: (A) three-dimensional stereogram; (B) enlarged plan view of the circular tube in the dotted region of the wind tunnel.

The dimensions of the test section were $150 \mathrm{~cm} \times 30$ $\mathrm{cm} \times 30 \mathrm{~cm}$. A circular tube with the fungal colony growing on it was vertically mounted into the test section. The aluminum circular tube has a length of $320 \mathrm{~mm}$ and an outer diameter of $9.5 \mathrm{~mm}$. The colony grew in a groove with a width of $2 \mathrm{~mm}$ and a length of $260 \mathrm{~mm}$ along the longitudinal tube. The dimensions of the contraction exit were $10 \mathrm{~cm} \times 10 \mathrm{~cm}$. Airborne spores were extracted by a sharp-edged sampler at the end of the contraction section. A wideband integrated bioaerosol sensor (WIBS) (Model NEO; Droplet Measurement Technologies Corp., USA) was used to count the aerosolized spores. The WIBS used UV xenon flashlamp to excite fluorescence for counting microbial particles. The diameters of detectable microbial particles ranged from 0.5 to $50 \mu \mathrm{m}$. The sample flow of the WIBS was $0.3 \mathrm{~L} / \mathrm{min}$.
The aerosolization test was carried out for a colony located in four different postions of the coil, as shown in Fig. 1(B). Consequently, four sweeping angles, i.e., $0^{\circ}$, $90^{\circ}, 180^{\circ}$ and $270^{\circ}$, were resulted. The $0^{\circ}$ means that the growing colony was parallel with the upstream airflow at the stagnation point, while $180^{\circ}$ designates the opposite to the stagnation point in the wake. The sweeping angles of $90^{\circ}$ and $270^{\circ}$ represent that the colonies were tangential to the upstream flow. Each aerosolization test was carried out only for a colony located in a specific position. In between the aerosolization tests, the test section was first cleaned with $70 \%$ ethanol and then purged by the filtered air. Each test lasted five minutes. The blowing air speeds in the test section ranged from $1-6 \mathrm{~m} / \mathrm{s}$. The temperature and relative humidity as measured at the end of the wind tunnel were $15-17^{\circ} \mathrm{C}$ and $50-55 \%$, respectively. All of the aerosolization tests were done in quintuplicates.

In addition, the aerosolized propagules from colonies at various sweeping angles were observed. When collecting the aerosolized propagules for observation, the sampler was replaced by a sterile microscope slide (26 $\mathrm{mm} \times 76 \mathrm{~mm}$ ) coated with Tween 20 . Tween 20 is a nonionic surfactant that is viscous and soluble in water. The collected propagules on the microscope slide were then photographed by an optical microscope (Model CX41; Olympus Corp., Japan).

The fungal species of $A$. niger was adopted as the test microorganism. This fungus is a common contaminant and one of the indicator organisms for mold contamination in air conditioning systems [16, 21]. A pure A. niger species (CICC 2089) was purchased from the Center of Industrial Culture Collection, China.

The fungal strains were first cultured on the malt extract agar plates at $24{ }^{\circ} \mathrm{C}$ for seven days before inoculation to the test tube. Fungal spore suspensions were prepared by washing the grown fungal colonies from the agar plates using sterilized water. The spore concentrations were checked using a brightline hemacytometer and were adjusted to $10^{6}$ spores $/ \mathrm{ml}$.

To supply nutrition for fungal growth on the test tube, approximately $0.7 \mathrm{ml}$ of melting nutrient agar was put into the groove of the tube. The nutrient agar was a mixture of peptone $(10 \mathrm{~g} / \mathrm{L})$, glucose $(40 \mathrm{~g} / \mathrm{L})$, and agar $(15 \mathrm{~g} / \mathrm{L})$. The nutrient agar was then curdled in seconds. Approximately $50 \mu \mathrm{l}$ of spore suspension was inoculated on each nutrient agar of the circular tube with a pipette. The inoculated circular tubes were then placed inside sterile glass tubes. A ball of sterile cotton containing approximately $2 \mathrm{ml}$ of sterile water was foisted into the bottom of the glass tube to maintain high relative humidity therein. The entire operation was carried out inside a clean bench (Model CDA-1080; Shangjing Corp., China) to prevent contamination of the air with suspended fungi. The circular tubes were then incubated in a dark incubator for either four or 10 days, to compare impact of different growth ages on the spore detachment. The temperature of the incubator was maintained at $28^{\circ} \mathrm{C}$ with a relative humidity $(\mathrm{RH})$ of $60 \%-65 \%$ by a saturated $\mathrm{K}_{2} \mathrm{SO}_{4}$ solution inside the incubator. The temperature and humidity were monitored by a temperature and humidity recorder (Model 179-DTH; Apresys Corp., USA) with an accuracy of $\pm 0.4^{\circ} \mathrm{C}$ and $\pm 3 \% \mathrm{RH}$. 
Fig. 2(A) and (B) shows photographs of the A. niger colonies growing on the circular tubes with different ages. The 4-day-old colony had a spore density of $(1.46 \pm 0.53)$ $\times 10^{7} \mathrm{H} / \mathrm{cm}^{2}$, while the density of the 10 -day-old colony was $(3.02 \pm 1.04) \times 10^{7} \# / \mathrm{cm}^{2}$. The spore density of the 10-day-old colony was approximately double that of the 4-day-old colony. The conidiophores of the older colony were much denser than those of the younger colony. Fig. 2(C) and (D) shows micrographs of the conidiophores. The conidial head of the 10-day-old colony was significantly larger than that of the 4-day-old colony. Furthermore, the spore chains of the older colony were longer.

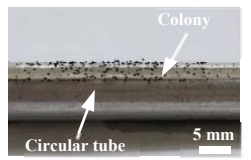

(A)

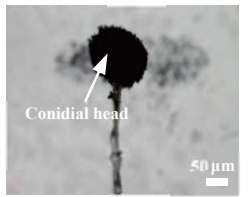

(C)

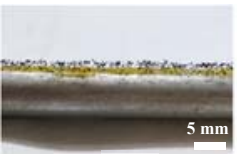

(B)

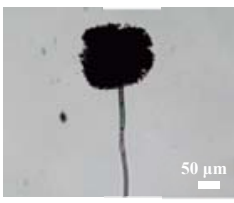

(D)
Fig. 2. Images of $A$. niger colonies, where (A) and (B) were lateral views of colonies on circular tubes, and (C) and (D) were micrographs of conidiophores: (A) and (C) 4-day-old colony; (B) and (D) 10-day-old colony.

\subsection{Numerical simulation of airflow surrounding to the circular tube}

In addition to aerosolization tests, numerical simulations of the airflow surrounding the circular tube in the wind tunnel were performed. The geometric model as shown in Fig. 3 was created. For brevity, the contraction section of the wind tunnel was not considered. The quadrilateral grid cells were generated by a commercial CFD preprocessing software ICEM (version 12.0.1). The total grid number was 122 kilo and the average grid size in the space was $2.3 \mathrm{~mm}$. The grid cells near the wind tunnel walls and the circular tube were refined in order to capture the near-wall effect within the boundary layer. All of the $y^{+}$values of the first near-wall grid cells were less than five. Therefore, velocity distribution in the viscous sub-layer can be well represented.

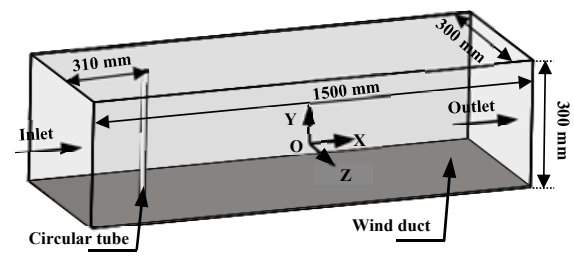

Fig. 3. Geometric model of the wind duct.

The governing equation of the fluid flow can be summarized as:

$$
\frac{\partial}{\partial t}(\rho \phi)+\frac{\partial}{\partial x_{j}}\left(\rho u_{j} \phi\right)=\frac{\partial}{\partial x_{j}}\left(\Gamma_{\phi, \mathrm{eff}} \frac{\partial \phi}{\partial x_{j}}\right)+S_{\phi}
$$

where $\rho$ is the air density, $\phi$ is a scalar variable, $t$ is time, $u_{j}$ is the velocity component in three directions $\left(x_{j}, j=1,2\right.$, 3 ) of the Cartesian coordinate system, $\Gamma_{\phi, \text { eff }}$ is the effective diffusion coefficient, and $S_{\phi}$ is the source term. By varying $\phi$, the above equation can represent the continuity, momentum and turbulence (the $\mathrm{RNG} k-\varepsilon$ model), respectively.

The RNG $k$ - $\varepsilon$ model proposed by Yakhot et al. [22] was adopted for turbulence modeling. The enhanced wall treatment was activated to employ the one-equation model in the viscosity-affected region of the wall boundary layers.

The inlet and exit boundaries were set as velocity inlet and free flow outlet, respectively. The solid walls were treated as the no-slip velocity boundary. The discretization scheme for momentum, turbulence was the second-order upwind type. The pressure and velocity were coupled by the SIMPLE algorithm. The continuity and momentum equations were thought to reach convergence when the ratio of the sum of the mass gain and loss on all boundaries to the overall mass gain in the wind duct was less than 1.0E-6. The commercial CFD software, FLUENT (version 12.0.16), was used to conduct the numerical simulation.

After the numerical simulation, the local air speeds in different positions of the circular tube were known. Then the drag force to aerosolize spores could be estimated. A spore was assumed to be an isolated sphere and the equation to estimate the resulting drag force can be found in our previous study [23]. The diameter of the $A$. niger spore was measured approximately $5 \mu \mathrm{m}$ by an optical microscope.

\section{Results}

\subsection{Detached propagules from colonies on the circular tube at different sweeping angles}

Fig. 4 shows the collected propagules of $A$. niger on microscope slides from the 4-day-old colony on the circular tube at different sweeping angles subjected to the inlet blowing speed of $5 \mathrm{~m} / \mathrm{s}$. At the sweeping angles of $0^{\circ}$ and $180^{\circ}$, only segregated spores were collected on the microscope slide (Fig. 4(A) and (C)). At the sweeping angles of $90^{\circ}$ and $270^{\circ}$, both segregated spores and spore aggregates with two or three spores were collected, as shown in Fig. 4(B) and (D). For the 10-day-old colony, the number of collected spores were much higher than that for the 4-day-old colony (Fig. 5). At the sweeping angles of $90^{\circ}$ and $270^{\circ}$, the collected propagules included segregated spores and spore aggregates with two or more spores, as shown in Fig. 5(B) and (D). 


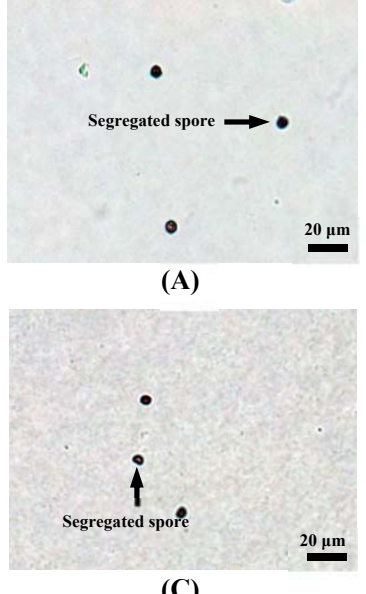

(C)

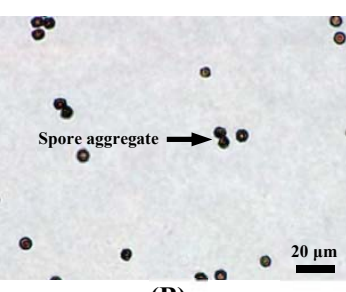

(B)

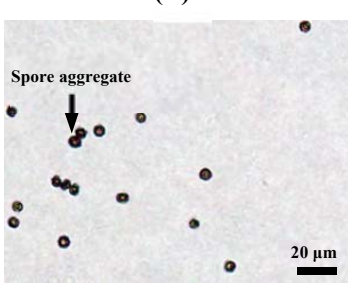

(D)
Fig. 4. Micrographs of collected propagules of $A$. niger at different sweeping angles for the 4-day-old colony by an optical microscope: (A) $0^{\circ}$; (B) $90^{\circ}$; (C) $180^{\circ}$; (D) $270^{\circ}$.

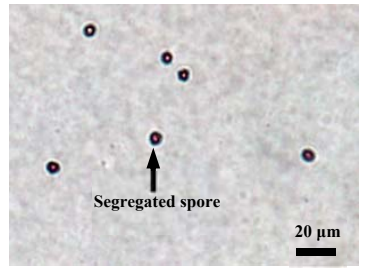

(A)

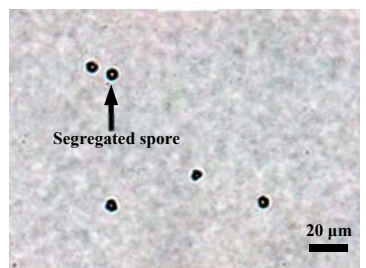

(C)

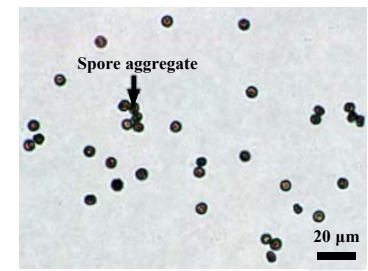

(B)

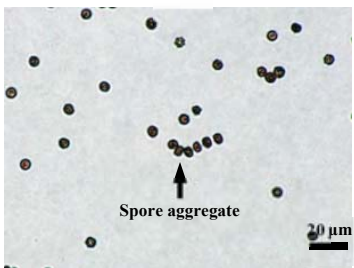

(D)
Fig. 5. Micrographs of collected propagules of $A$. niger at different sweeping angles for the 10-day-old colony by an optical microscope: (A) $0^{\circ}$; (B) $90^{\circ}$; (C) $180^{\circ}$; (D) $270^{\circ}$.

\subsection{Quantity of collected spores from colonies on the circular tube at different sweeping angles}

The quantity of collected spores from colonies on the circular tube at different sweeping angles was counted by the bioaerosol sensor. Table 1 presents the collected spores as a variable dependent on the sweeping angle and the inlet blowing speed, for the 4-day-old colony. The quantity of aerosolized spores changed greatly with the position of the colony, i.e., the sweeping angle of the airflow to the colony. The counted spores at the inlet blowing speed of $2.75 \mathrm{~m} / \mathrm{s}$ were approximately $475 \pm 36$ and $507 \pm 42$ at the sweeping angles of $90^{\circ}$ and $270^{\circ}$, respectively. In contrast, only dozens of spores were detected for the sweeping angles of $0^{\circ}$ and $180^{\circ}$. The quantity of collected spores at the sweeping angles of $90^{\circ}$ and $270^{\circ}$ was approximately 8.5 times that at the sweeping angles of $0^{\circ}$ and $180^{\circ}$. Similarly, as shown in Table 2, the quantity of collected spores from the 10-day-old colony at the sweeping angles of $90^{\circ}$ and $270^{\circ}$ was approximately 6.5 times that at the sweeping angles of $0^{\circ}$ and $180^{\circ}$ for the inlet blowing speed of $3.00 \mathrm{~m} / \mathrm{s}$. The results indicated that the spores of the colonies at the sweeping angles of $90^{\circ}$ and $270^{\circ}$ were much more easily aerosolized than that at the sweeping angles of $0^{\circ}$ and $180^{\circ}$.

On the other hand, the quantity of aerosolized spores increased with the blowing air speed. Only dozens of spores were detected when the inlet air speed was less than $2.50 \mathrm{~m} / \mathrm{s}$ from the 4-day-old colony, as shown in Table 1 . When the inlet air speed reached $2.75 \mathrm{~m} / \mathrm{s}$, the quantity of collected spores at the sweeping angles of $90^{\circ}$ and $270^{\circ}$ under the inlet air speed of $2.75 \mathrm{~m} / \mathrm{s}$ was approximately six times that under the inlet air speed of $2.50 \mathrm{~m} / \mathrm{s}$. This indicates that the inlet air speed of $2.75 \mathrm{~m} / \mathrm{s}$ was the threshold air speed for remarkable detachment of spores from the 4-day-old colony at the sweeping angles of $90^{\circ}$ and $270^{\circ}$. Similarly, for the 10-day-old colony, the quantity of collected spores at the sweeping angles of $90^{\circ}$ and $270^{\circ}$ under the inlet air speed of $2.00 \mathrm{~m} / \mathrm{s}$ was approximately five times that under the inlet air speed of $1.75 \mathrm{~m} / \mathrm{s}$. In addition, the counted spores from the 10-dayold colony at the sweeping angle of $0^{\circ}$ under the inlet air speed of $5.75 \mathrm{~m} / \mathrm{s}$ were approximately 4.5 times that under the inlet air speed of $5.50 \mathrm{~m} / \mathrm{s}$. Thus, the inlet speeds of $2.00 \mathrm{~m} / \mathrm{s}$ at the sweeping angles of $90^{\circ}$ and $270^{\circ}$ and 5.75 $\mathrm{m} / \mathrm{s}$ at the sweeping angle of $0^{\circ}$ were identified as the threshold values for remarkable spore detachment from the 10-day-old colony.

Note that the above speed values are the inlet air speeds of the wind tunnel. When the airflow sweeps the circular tube, the flow may accelerate and decelerate near the tube. The local air speeds at the conidial head of the colony for spore detachment can be much different from the inlet air speed. The conidial head is a sporogenous structure that includes a vesicle, metulae, phialides, and spore chains. The local speed at the conidial head was determined by the numerical simulation in the next section.

Table 1. Variation of collected spores for the 4-day-old colony on the circular tube at different sweeping angles subjected to various inlet air speeds

\begin{tabular}{ccccc}
\hline $\begin{array}{c}\text { Inlet air } \\
\text { speed } \\
(\mathbf{m} / \mathbf{s})\end{array}$ & $\mathbf{0}^{\mathbf{0}}$ & $\mathbf{9 0}^{\mathbf{o}}$ & $\mathbf{1 8 0}^{\mathbf{0}}$ & $\mathbf{2 7 0}^{\mathbf{0}}$ \\
\cline { 2 - 5 } & $17 \pm 7$ & $24 \pm 8$ & $13 \pm 6$ & $23 \pm 9$ \\
1.00 & $33 \pm 10$ & $40 \pm 15$ & $26 \pm 9$ & $43 \pm 16$ \\
2.00 & $51 \pm 14$ & $73 \pm 14$ & $30 \pm 7$ & $68 \pm 19$ \\
2.25 & $53 \pm 18$ & $78 \pm 13$ & $32 \pm 7$ & $85 \pm 10$ \\
2.50 & $56 \pm 16$ & $475 \pm 36$ & $41 \pm 10$ & $507 \pm 42$ \\
2.75 & $78 \pm 24$ & $493 \pm 80$ & $46 \pm 10$ & $534 \pm 79$ \\
3.00 & $113 \pm 33$ & $712 \pm 69$ & $91 \pm 15$ & $746 \pm 78$ \\
4.00 & $206 \pm 70$ & $1260 \pm 124$ & $173 \pm 53$ & $1150 \pm 126$ \\
5.00 & $323 \pm 68$ & $1883 \pm 164$ & $255 \pm 76$ & $1546 \pm 191$ \\
\hline 6.00 & & & &
\end{tabular}


Table 2. Variation of collected spores for the 10-day-old colony on the circular tube at different sweeping angles subjected to various inlet air speeds

\begin{tabular}{ccccc}
\hline $\begin{array}{c}\text { Inlet air } \\
\text { speed } \\
(\mathbf{m} / \mathbf{s})\end{array}$ & \multicolumn{4}{c}{ Quantity of collected spores (\#) } \\
\cline { 2 - 5 } & $\mathbf{0}^{\mathbf{o}}$ & $\mathbf{9 0}^{\mathbf{o}}$ & $\mathbf{1 8 0}^{\mathbf{o}}$ & $\mathbf{2 7 0}^{\mathbf{0}}$ \\
\hline 1.00 & $21 \pm 6$ & $32 \pm 5$ & $16 \pm 5$ & $35 \pm 11$ \\
1.25 & $25 \pm 7$ & $40 \pm 9$ & $19 \pm 5$ & $38 \pm 5$ \\
1.50 & $32 \pm 4$ & $42 \pm 5$ & $27 \pm 5$ & $43 \pm 8$ \\
1.75 & $45 \pm 8$ & $46 \pm 8$ & $31 \pm 6$ & $49 \pm 10$ \\
2.00 & $57 \pm 14$ & $237 \pm 21$ & $45 \pm 9$ & $252 \pm 20$ \\
3.00 & $96 \pm 27$ & $646 \pm 112$ & $82 \pm 25$ & $752 \pm 148$ \\
4.00 & $163 \pm 45$ & $1113 \pm 178$ & $143 \pm 29$ & $1082 \pm 123$ \\
5.00 & $204 \pm 72$ & $1681 \pm 126$ & $251 \pm 41$ & $1322 \pm 139$ \\
5.25 & $217 \pm 56$ & $1738 \pm 96$ & $258 \pm 53$ & $1547 \pm 90$ \\
5.50 & $223 \pm 60$ & $1915 \pm 92$ & $263 \pm 50$ & $1839 \pm 118$ \\
5.75 & $1009 \pm 89$ & $1996 \pm 142$ & $272 \pm 57$ & $2076 \pm 108$ \\
6.00 & $1136 \pm 101$ & $2037 \pm 279$ & $279 \pm 59$ & $2185 \pm 272$ \\
\hline
\end{tabular}

\subsection{Velocity distribution of the airflow surrounding the circular tube and aerosolized forces for spore detachment}

Fig. 6 presents the velocity distribution surrounding the circular tube under two different inlet air velocities. The velocity contour was distributed nearly symmetrically. The high velocity of the airflow was located in both lateral sides of the circular tube and the low velocity was positioned on the windward and leeward sides. The stagnation point could be clearly viewed. There were two flow separation points in the leeward sides. A trailing vortex was then developed on the downstream side where the air velocity was much lower than that of the upstream velocity. Based on the above, the local air speed at the sweeping angles of $90^{\circ}$ and $270^{\circ}$ was significantly higher than the upstream air speed; while the local speed at the sweeping angles of $0^{\circ}$ and $180^{\circ}$ was much lower.

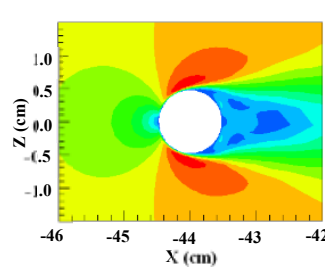

(A)

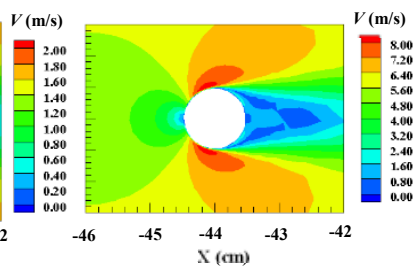

(B)
Fig. 6. Velocity distribution of the airflow surrounding the circular tube at different inlet air velocities: (a) $1.50 \mathrm{~m} / \mathrm{s}$; (b) 5.75 $\mathrm{m} / \mathrm{s}$.

Table 3 presents the local air speed at the conidial head of the colony growing on the circular tube as a variable of the inlet air speed. The height of the conidial head of the A. niger from the circular tube was assumed to be $2 \mathrm{~mm}$ (Fig. 2(B)). At the sweeping angle of $0^{\circ}$, the colony was very close to the stagnation point. However, at a position with $2 \mathrm{~mm}$ away from the stagnation point, the local air speed was nonzero. This shows that the air speed changed greatly when approaching the tube wall.

For the 4-day-old colony, Table 3 shows that the local air speeds of 3.70 and $3.68 \mathrm{~m} / \mathrm{s}$ were the threshold air speeds for remarkable detachment of spores at the sweeping angles of $90^{\circ}$ and $270^{\circ}$, corresponding to an inlet air speed of $2.75 \mathrm{~m} / \mathrm{s}$. The local air speeds were highly different from the inlet air speed. The local air speeds of 2.71 and $2.70 \mathrm{~m} / \mathrm{s}$ were identified as the threshold values for remarkable spore detachment from the 10-day-old colony at the sweeping angles of $90^{\circ}$ and $270^{\circ}$, corresponding to an inlet speed of $2.00 \mathrm{~m} / \mathrm{s}$. Similarly, the local air speed of $2.74 \mathrm{~m} / \mathrm{s}$ was required to aerosolize spores from the 10-day-old colony at the sweeping angle of $0^{\circ}$, corresponding to an inlet speed of $5.75 \mathrm{~m} / \mathrm{s}$. Although the inlet blowing air speeds were different, the threshold local air speeds for remarkable detachment of spores under sweeping angles of $0^{\circ}, 90^{\circ}$ and $270^{\circ}$ for the 10-day-old colony were quite similar.

Table 3. Local air speeds at the conidial head of colonies on the circular tube at different sweeping angles.

\begin{tabular}{ccccc}
\hline \multirow{2}{*}{$\begin{array}{c}\text { Inlet air speed } \\
(\mathbf{m} / \mathbf{s})\end{array}$} & \multicolumn{4}{c}{$\begin{array}{c}\text { Local air speed at the conidial head } \\
(\mathbf{m} / \mathbf{s})\end{array}$} \\
\cline { 2 - 5 } & $\mathbf{0}^{\mathbf{0}}$ & $\mathbf{9 0}^{\mathbf{0}}$ & $\mathbf{1 8 0}^{\mathbf{0}}$ & $\mathbf{2 7 0}^{\mathbf{0}}$ \\
\hline 2.00 & 0.92 & 2.71 & 0.42 & 2.70 \\
2.75 & 1.28 & 3.70 & 0.60 & 3.68 \\
5.75 & 2.74 & 7.64 & 1.26 & 7.59 \\
\hline
\end{tabular}

Table 4 presents the drag force exerted on an isolated spore as a variable of the air speed. The numerical simulation shows that the local air speed at the sweeping angle of $90^{\circ}$ was very similar to that at the sweeping angle of $270^{\circ}$. For preventing redundancy, the sweeping angle of $90^{\circ}$ was taken as an example to estimate the threshold drag force for remarkable spore detachment. Based on the local threshold air speed of $3.70 \mathrm{~m} / \mathrm{s}$ at the sweeping angle of $90^{\circ}$ for the 4-day-old colony, the threshold drag force was estimated to be $3.51 \mathrm{nN}$. Similarly, for the 10-day-old colony, the threshold drag forces were estimated to be $2.48 \mathrm{nN}$ at the sweeping angle of $90^{\circ}$ and $2.51 \mathrm{nN}$ at the sweeping angle of $0^{\circ}$.

Table 4. Drag force on a single isolated spore as a variable dependent on the threshold local air speed for spore aerosolization.

\begin{tabular}{cccc}
\hline $\begin{array}{c}\text { Local air } \\
\text { speed (m/s) }\end{array}$ & $\boldsymbol{R}_{\mathrm{p}}$ & $\begin{array}{c}\text { Drag } \\
\text { coefficient } \\
\left(\boldsymbol{C}_{\mathbf{D})}\right.\end{array}$ & $\boldsymbol{F}_{\mathbf{D}}(\mathbf{n N})$ \\
\hline 2.71 & 0.92 & 28.72 & 2.48 \\
2.74 & 0.93 & 28.43 & 2.51 \\
3.70 & 1.25 & 21.78 & 3.51 \\
\hline
\end{tabular}

The drag forces required to aerosolize spores in the wind tunnel were compared with the forces required to detach A. niger spores from colonies using an atomic 
force microscope (AFM). The AFM-measured detachment forces were reported in our previous study [23]. The detachment forces were reestimated when a spore chain as a whole was detached, as shown in Table 5. Combined with our previous study, the average force required to detach a detachment unit from the 4-day-old colony ranged from $3.27 \mathrm{nN}$ [23] to $4.59 \mathrm{nN}$. A detachment unit might be a segregated spore or a spore chain containing several spores. Similarly, the average force for the 10-day-old colony ranged from 1.98 [23] to $3.05 \mathrm{nN}$. The results revealed that the drag forces required to aerosolize spores from the two growth ages' colonies were in accordance with the ranges of the detachment forces measured by the AFM.

Table 5. Force required to detach a detachment unit from A. niger colonies at two different ages in five repeated tests.

\begin{tabular}{|c|c|c|c|c|c|c|c|c|c|c|c|}
\hline \multirow[t]{2}{*}{$\begin{array}{l}\text { Growth age } \\
\text { (days) }\end{array}$} & \multicolumn{5}{|c|}{ Force to detach spores (nN) } & \multicolumn{5}{|c|}{$\begin{array}{l}\text { Number of detachment units stuck to } \\
\text { the cantilever }\end{array}$} & \multirow[t]{2}{*}{$\begin{array}{l}\text { Average force to detach a } \\
\text { detachment unit (nN) }\end{array}$} \\
\hline & 1st & 2nd & 3rd & 4th & 5th & 1st & 2nd & 3rd & 4th & 5th & \\
\hline 4 & 85 & 87 & 86 & 46 & 54 & 13 & 21 & 20 & 12 & 13 & $4.59 \pm 1.10$ \\
\hline 10 & 37 & 34 & 35 & 36 & 25 & 12 & 12 & 11 & 14 & 7 & $3.05 \pm 0.38$ \\
\hline
\end{tabular}

\section{Conclusions}

This study conducted the aerosolizaition tests of Aspergillus niger spores from colonies in different positions on a circular tube in a wind tunnel. The numerical simulation of airflow surrounding the circular tube was performed to estimate the drag force for aerosolization of the fungal spores. The following conclusions can be drawn from the results.

The aerosolized spores changed greatly with the grown positions of the colony on the coil. The quantity of collected spores when the colonies were tangential to the upcoming airflow was approximately 8.5 times that when the colonies were located parallel with the upcoming airflow, subjected to the inlet blowing speed of $2.75 \mathrm{~m} / \mathrm{s}$ for the 4-day-old colony. For the 10-day-old colony, the collected spores when the colonies were tangential to the upcoming airflow were approximately 6.5 times that when the colonies were parallel with the upcoming airflow, for the inlet blowing speed of $3.00 \mathrm{~m} / \mathrm{s}$. The local air speeds on different positions of the coil can be highly different from the inlet air speed. The drag force to aerosolize the fungal spores should be calculated based on the local air speeds in different positions of the tube. The aerosolization tests yielded similar threshold forces for remarkable spore detachment, as compared with the AFM measurements.

\section{Acknowledgements}

This work was supported by the Natural Science Foundation of China for Distinguished Young Scholars (Grant No.: 51622804).

\section{References}

1. E. Acerbi, C. Chénard, D. Miller, N.E. Gaultier, C.E. Heinle, V.W.C. Chang, A. Uchida, D.I. DrautzMoses, S.C. Schuster, F.M. Lauro, Indoor air 27, 2 (2017)

2. Z. Lu, W.Z. Lu, J.L. Zhang, D.X. Sun, Build. Environ. 44 (2009)
3. J. Mensah-Attipoea, S. Saarib, A.M. Veijalainena, P. Pasanena, J. Keskinenb, J.T.T. Leskinenc, T. Reponen, Sci. Total. Environ. 547 (2016)

4. A.J. Prussin, D.O. Schwake, L.C. Marr, Build. Environ. 123 (2017)

5. J.C. Luongo, S.L. Miller, Build. Environ. 105 (2016)

6. A.J. Prussin, L.C. Marr, Microbiome 3 (2015)

7. P. Hugenholtz, J.A. Fuerst, Appl. Environ. Microbiol. 58 (1992)

8. R.B. Simmons, L.J. Rose, S.A. Crow, D.G. Ahearn, Curr. Microbiol. 39 (1999)

9. P.C. Kemp, H.G. Neumeister-Kemp, B. Esposito, AIHA J. 64 (2003)

10. Y. Wu, A.L. Chen, I. Luhung, E.T. Gall, Q.L. Cao, V.W.C Chang, W.W. Nazaroff, Atmos. Environ. 144 (2016)

11. Z.J. Liu, S.Y. Ma, G.Q. Cao, C. Meng, B.J. He, Energ. Buildings 177 (2018)

12. R.L. Gorny, T. Reponen, S.A. Grinshpun, K. Willeke, Atmos. Environ. 35 (2001)

13. A. Bakker, J.A. Siegel, M.J. Mendell, J. Peccia, Indoor Air 28 (2018)

14. P. Krauter, A. Biermann, Appl. Environ. Microbiol. 73 (2007)

15. S.M. Knudsen, L. Gunnarsen, A.M. Madsen, Build. Environ. 122 (2017)

16. A.G. Li, J. Xiong, L.Z. Yao, L. Gou, W.R Zhang, Build. Environ. 104 (2016)

17. A.M. Madsen. Appl. Environ. Microbiol. 78 (2012)

18. S.K. Sivasubramani, R.T. Niemeier, T. Reponen, S.A. Grinshpun, Sci. Total Environ. 329 (2004)

19. K.D.R. Wadia, H.A. McCartney, D.R. Butler, Mycol. Res. 102 (1998)

20. J.Y. Jang, M.C. Wu, W.J. Chang, Int. J. Heat Mass Transfer 39 (1996)

21. Z.J. Liu, Z.Q. Zhu, Y.X. Zhu, W. Xu, H. Li, Energ. Buildings 103 (2015)

22. V. Yakhot, S.A. Orszag, S. Thangam, T.B. Gatski, C.G. Speziale, Phys. Fluids A 4 (1992)

23. X. Li, T.F. Zhang, S.G. Wang, Indoor Air 28 (2018) 